University of Montana

ScholarWorks at University of Montana

8-1998

\title{
Pair Interactions in Red-Faced Warblers
}

P. M. Barber

Thomas E. Martin

University of Montana - Missoula, tom.martin@umontana.edu

K. G. Smith

Follow this and additional works at: https://scholarworks.umt.edu/wildbio_pubs

Part of the Life Sciences Commons

Let us know how access to this document benefits you.

\section{Recommended Citation}

Barber, P. M.; Martin, Thomas E.; and Smith, K. G., "Pair Interactions in Red-Faced Warblers" (1998).

Wildlife Biology Faculty Publications. 42.

https://scholarworks.umt.edu/wildbio_pubs/42

This Article is brought to you for free and open access by the Wildlife Biology at ScholarWorks at University of Montana. It has been accepted for inclusion in Wildlife Biology Faculty Publications by an authorized administrator of ScholarWorks at University of Montana. For more information, please contact scholarworks@mso.umt.edu. 


\title{
PAIR INTERACTIONS IN RED-FACED WARBLERS ${ }^{1}$
}

\author{
PATRICIA M. BARBeR ${ }^{2}$ \\ Department of Biological Sciences, University of Arkansas, Fayetteville, AR 72701
}

THOMAS E. MARTIN

USGS Biological Resources Division, Montana Cooperative Wildlife Research Unit, Avian Studies Program, University of Montana, Missoula, MT 59812

\author{
KIMBERLY G. SMITH \\ Department of Biological Sciences, University of Arkansas, Fayetteville, AR 72701
}

\begin{abstract}
Forty pairs of breeding Red-faced Warblers (Cardellina rubrifrons) were observed in 1992 and 1993 on the Mogollon Rim, Arizona. Intrusions by extra-pair males, interactions between pair members, and other pair interaction behaviors were recorded. The majority of intrusions occurred during the building stage of the nesting cycle. Males responded to intrusions during nest building by decreasing intra-pair distance. Males maintained shorter intra-pair distances by following the female when she initiated movements and by not initiating pair movements themselves. Intra-pair distances were as short or shorter during the incubation period as during nest building, and were shorter during incubation than during egg laying. Males continued to follow females beyond the expected fertile period. Possible explanations for continued mate following include: males guard their mates against predators, males guard their paternity for future nesting attempts, and males respond to extra-pair male intrusions, which continue during incubation.
\end{abstract}

Key words: Cardellina rubrifrons, mate guarding, pair interactions, Red-faced Warbler.

\section{INTRODUCTION}

Mate guarding, whereby a male attempts to restrict access to his mate by other males, potentially increases confidence of paternity (Arvidsson 1992, Birkhead and Møller 1992, Sundberg 1994). Loss of paternity has direct fitness consequences for males, but confidence of paternity also can affect fitness by influencing male willingness to contribute to breeding efforts in species in which males aid in rearing young (Møller 1988, Westneat 1988, Dixon et al. 1994). Mate guarding is a behavioral response to fertility of a mate; to effectively guard against extra-pair paternity, a male should remain closer to a female during her fertile period and follow her more often when she initiates movements. If such behaviors serve to protect paternity, a male should not necessarily remain near the female or follow her during her nonfertile period. Instead, males should initiate more movements during this nonfertile period than during the fertile period. Thus, males should respond to female fertility by (1) decreasing intra-pair distance, (2)

\footnotetext{
' Received 18 August 1997. Accepted 10 February 1998.

2 Current address: Archbold Biological Station, P. O. Box 2057, Lake Placid, FL 33862-2057, e-mail: pbarber@archbold-station.org
}

increasing the rates of following female-initiated movements, and (3) decreasing initiation of movements during the fertile period compared to the nonfertile period (Birkhead 1979).

Mate guarding has been documented in more than 50 species of birds (Birkhead et al. 1987), although few have dealt with forest dwelling species (Hobson and Sealy 1986, Gilbert 1994). Low visibility situations such as forested environments are likely to provide excellent opportunities for successful extra-pair copulations.

Here we focus on Red-faced Warblers (Cardellina rubrifrons), a small, forest dwelling, insectivorous Neotropical migrant (Monson 1957, Harrison 1984, Martin and Barber 1995). This species is a socially monogamous breeder, in which pairs form after birds arrive on the breeding grounds. Individuals are bold and curious, not secretive; they quickly return to nesting activities such as nest building and feeding young after minor disturbances in their territory such as researchers walking through the area. Although Red-faced Warblers generally are considered monotypic (Pyle et al. 1987), we have observed within-pair sexual dimorphism (P. Barber and T. Martin, unpubl. data), allowing easy identification of each individual pair member. Redfaced Warblers nest on the ground making direct 
observation of nest contents possible and determination of nesting stage straightforward.

This study had three objectives: (1) to document and quantify pair interaction behaviors among nesting stages, (2) determine whether pair interaction patterns constitute mate guarding, and (3) determine whether intrusions by non-pair males influence pair interactions.

\section{METHODS}

\section{STUDY SITE}

Data were collected throughout 1992 and 1993 breeding seasons (May-July) in central Arizona on the Mogollon $\operatorname{Rim}(2,600 \mathrm{~m})$, in Coconino and Apache-Sitgreaves National Forests. Study plots were either shallow drainages dominated by canyon maple (Acer grandidentatum) and quaking aspen (Populus tremuloides) or deep canyons dominated by white fir (Abies concolor) and Douglas fir (Pseudotsuga menziesii). Shallow drainages only dropped about $25 \mathrm{~m}$, whereas deep canyon plots dropped as much as $75 \mathrm{~m}$ below the elevation of the rim. Additional canopy tree species found on plots included ponderosa pine (Pinus ponderosa), southwestern white pine ( $P$. flexilis), and Gambel oak (Quercus gambelii). The understory contained primarily canyon maple, New Mexico locust (Robina neomexicana), and saplings of the larger tree species (for detailed vegetation description, see Martin 1997).

\section{BEHAVIORAL OBSERVATIONS}

Forty pairs of Red-faced Warblers were observed. Focal pair observations began as soon as pairs started establishing territories. Each pair was monitored between 05:45 and 12:00 for up to $60 \mathrm{~min}$ a day, every $2-3$ days until eggs hatched or the nest failed. Nesting stage of each focal pair and plot type were noted. During the egg laying and incubation stages of nesting, data collected when the female was on the nest were excluded. During each observation, the following data were recorded every $60 \mathrm{sec}$ : distance between pair members, activity of each pair member (defined as collecting nest material, building nest, singing, preening, foraging, flying, and perching), and position of each pair member relative to its mate (above or below). Pair movements were monitored continuously, and we recorded which sex initiated a movement, distance of the movement, and if the mate followed within $30 \mathrm{sec}$. An intrusion occurred when a male other than the female's mate was on the territory near the female. Each intrusion was recorded and used as an index of extra-pair copulatory pressure. Intrusion rates were calculated as number of intrusions witnessed during a watch divided by number of samples (minute observations).

\section{STATISTICAL ANALYSIS}

All continuous data were tested for normality. Mean intra-pair distance and intrusion rate were square root transformed. Mean intra-pair distance, female initiated movements during incubation, and rate of males following females during egg laying differed between years and were analyzed separately. All other variables did not differ and were pooled across years. $t$-tests (SAS 1985 ) were used to determine any biases in behavioral observations for both time of day and season, by dividing in half the range of times and dates for observations during each stage. Intra-pair distances did not vary with time of day or season, so samples were pooled. Nested ANOVA (SAS 1985) was used to examine differences in intra-pair distances among stages. Individual observations were nested within each pair, resulting in a mean intra-pair distance, weighted by number of 1 -min samples. The Least Squares Means (LSM) method was used to conduct two-way comparisons among all stages, while simultaneously correcting for experimentwise error.

Number of intrusions at each stage, vertical position of each pair member relative to its mate (at each stage), the pair member more likely to initiate movements (at each stage), whether males tended to follow female-initiated movements similarly among nesting stages, and intrusion rates versus intra-pair distances among stages, were compared. Significance levels were set at 0.05. Kruskal-Wallis tests (SAS 1985) were used to determine whether differences in vertical position frequencies occurred among stages.

Female movements toward the nest or male were excluded from calculations of movement initiation and likelihood of being followed. Movements toward the male were excluded because a male does not need to follow his mate when she is decreasing the distance between them. Movements toward the nest were excluded because a male would often perch where he could easily observe the female flying between 


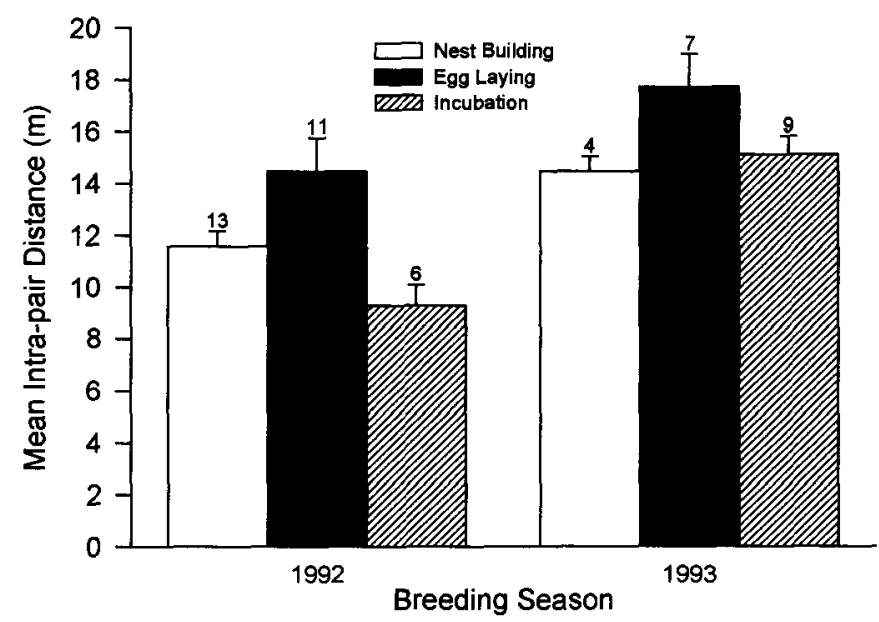

FIGURE 1. Mean distance between pairs of Red-faced Warblers during each nesting stage each year. Bars represent SE. Nested ANOVA was used to test for differences in distances among stages and between years. $\left(1992 F_{20.513}=23.6, P<0.001 ; 1993 F_{15.528}=6.6, P<0.001\right)$. Numbers above bars are sample size.

the nest and the location where she was collecting nesting material.

The percentage of observations in which pair members were engaged in each activity was calculated and compared with relative positions of pair members to each other to determine whether activities influenced differences in height. These comparisons were made because differences in behavioral activities, such as singing versus nest building, may dictate differences in height position in the foliage.

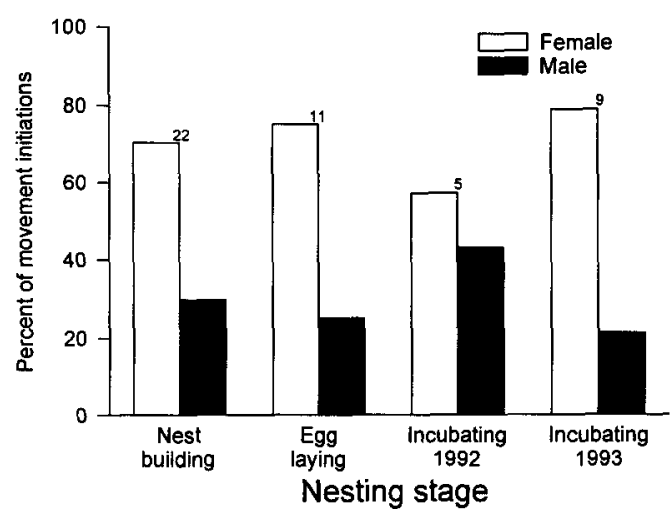

FIGURE 2. Comparison of percent of movements initiated by each member of Red-faced Warbler pairs during nest building $\left(G_{1}=66.6, P<0.01\right)$, egg laying $\left(G_{1}=11.5, P=0.05\right), 1992$ incubation $\left(G_{1}=0.7, P\right.$ $>0.10)$, and 1993 incubation $\left(G_{1}=18.4, P=0.001\right)$. Numbers above bars are sample size.

\section{RESULTS}

\section{INTRA-PAIR DISTANCE}

Mean intra-pair distance differed among nesting stages in both years (Fig. 1). The distance between pair members was less during nest building than during egg laying, in one year (1992 LSM, $P<$ $0.09 ; 1993$ LSM, $P<0.01$ ). In 1992, pairs were closer together during incubation than during nest building (LSM, $P<0.03$ ) or egg laying (LSM, $P$ $=0.001$ ). In 1993, pairs were closer together during nest building $(P<0.01)$ and tended to be during incubation $(P=0.07)$ than egg laying. Intrapair distance did not differ between nest building and incubation (LSM, $P>0.10$ ).

\section{MOVEMENT INITIATIONS}

The ratio of female to male initiation of movements was similar during nest building and egg laying stages in 1992 and 1993, so these data were pooled. Females initiated movements more often than males during nest building (Fig. 2) and egg laying. Initiation of movements during the incubation stage varied between years. Females did not initiate more movements than males during the incubation stage in 1992, but did initiate more movements than males during the incubation stage of 1993. Rates at which females were followed by their mates did not differ between years (Table 1) or across stages within years, except during egg laying in 1992 
TABLE 1. Percent of movements initiated by female Red-faced Warblers in which they were followed by their mates during nest building, egg laying, and incubation. Sample sizes are presented in parentheses. Data were tested between years $\left(G_{1}=2.4, P>0.1\right)$ and among stages within years $\left(1993 G_{1}=1.7, P>\right.$ $0.4)$.

\begin{tabular}{lll}
\hline \hline \multicolumn{1}{c}{ Nesting stage } & Followed & Not followed \\
\hline Nest building & $35.4(97)$ & $64.6(177)$ \\
Egg laying (1992) & $70.0(14)$ & $30.0(6)$ \\
Egg laying (1993) & $12.5(1)$ & $87.5(7)$ \\
Incubating & $41.0(25)$ & $59.0(36)$ \\
\hline
\end{tabular}

when males were most likely to follow their mates $\left(G_{1}=8.2, P<0.01\right)$.

\section{INTRUSIONS}

Intrusion rates were similar between years for each stage, so years were pooled. Intrusions were more frequent during nest building than during egg laying or incubation $\left(G_{2}=11.5, P\right.$ $<0.01$; Fig. 3). Mean intra-pair distance was negatively correlated with intrusion rate during nest building (Fig. 4A) and over all stages pooled (Fig. 4B).

\section{MATE POSITION}

Males were positioned higher in the vegetation relative to their mate at each nesting stage (Fig. 5). Pair members spent similar amounts of time during the nest building stage perching, preening, and foraging. However, males sang during $56.0 \%(n=184)$ of observations, whereas females spent $61.1 \%(n=329)$ of the time engaged in activities on the ground (Table 2).

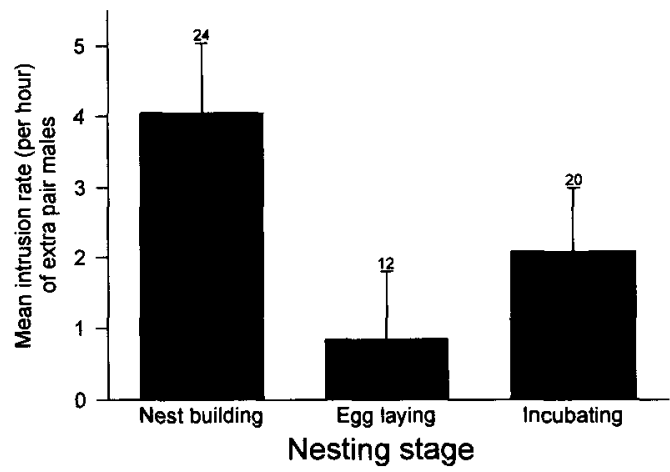

FIGURE 3. Mean intrusion rate $\left(\mathrm{hr}^{-1}\right)$ of male Redfaced Warblers into territories of nesting pairs of Redfaced Warblers at each nesting stage. Bars represent $\mathrm{SE}$. Numbers above bars are sample size.

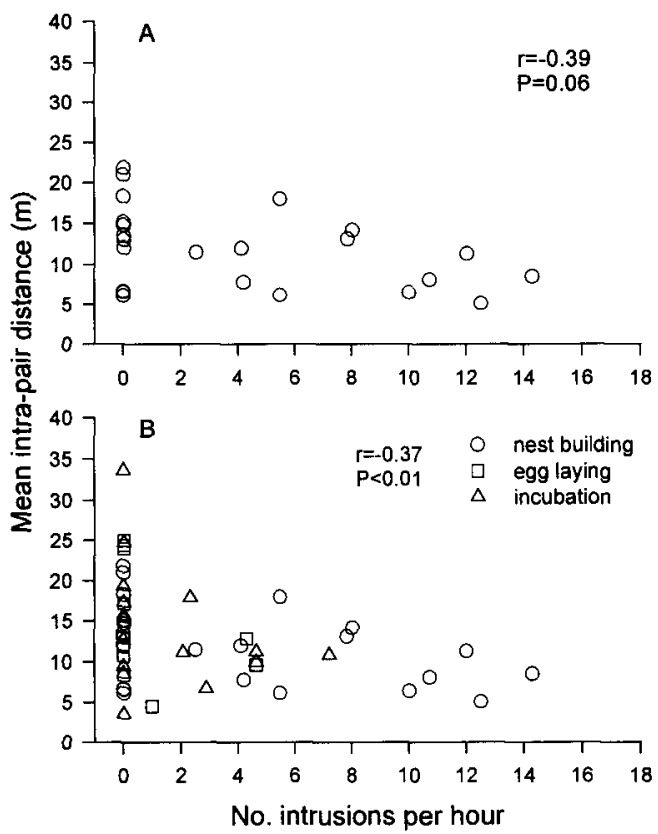

FIGURE 4. (A) Intrusion rate of male Red-faced Warblers compared with intra-pair distance during nest building ( $r=-0.39, P<0.06, n=24)$. Intrusion rate was measured as number of intrusions $\mathrm{hr}^{-1}$. (B) Intrusion rate of male Red-faced Warblers compared with intra-pair distance across all stages $(r=-0.37, P<$ 0.01 , nest building $n=24$, egg laying $n=12$, incubation $n=20$ ). Intrusion rate was measured as number of intrusions $\mathrm{hr}^{-1}$.

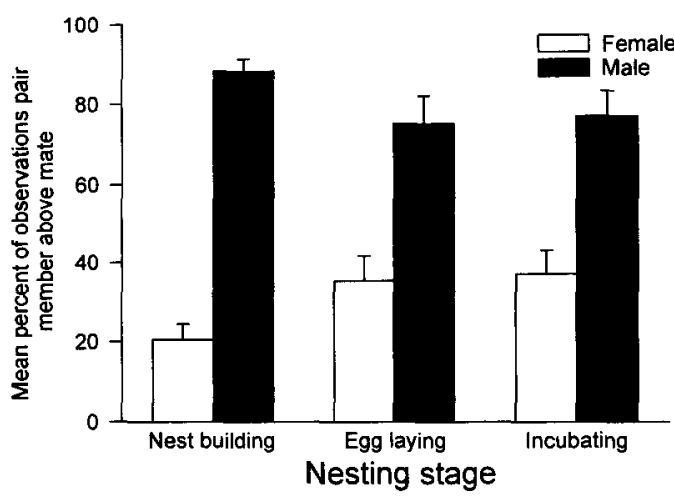

FIGURE 5. Mean percent of observations during which one member of a pair of Red-faced Warblers was higher than the other at each nesting stage (nest building $G_{1}=217.1, P=0.001$; egg laying $G_{1}=40.2$, $P<0.05$; incubation $G_{1}=104.1, P=0.001$ ). Bars represent SE. 
TABLE 2. Percent of observations adult Red-faced Warblers engaged in different activities during nest building, based on 60 -sec sampling. Sample sizes are presented in parentheses.

\begin{tabular}{lcc}
\hline \multicolumn{1}{c}{ Activity } & Female & Male \\
\hline Singing & $0(0)$ & $60.2(103)$ \\
Building nest & $44.0(128)$ & $0(0)$ \\
Collecting nest material & $13.8(40)$ & $0(0)$ \\
Chasing intruder & $0(0)$ & $0.6(1)$ \\
Perching & $28.5(83)$ & $32.2(55)$ \\
Foraging & $11.3(33)$ & $3.5(6)$ \\
Flying & $2.4(7)$ & $3.5(6)$ \\
Total & $100.0(291)$ & $100.0(171)$ \\
\hline
\end{tabular}

\section{DISCUSSION}

Male Red-faced Warblers clearly follow their mates. Males appear to decrease their movement initiations and intra-pair distance in response to intrusions. Although intra-pair distance among nesting stages differed between years, the patterns were effectively the same. Pair members remained closer together during nest building than during egg laying. The nest building stage also was important relative to copulatory activity. The majority of copulations for most species occur prior to egg laying, even though females continue to be fertile until the penultimate egg is laid (Birkhead and Møller 1993), and this appears to be true for Red-faced Warblers in which the majority of copulatory activity occurred during nest-building.

Most species of birds have been found to stop or to decrease mate-guarding once the female is no longer fertile, such as late egg-laying or incubation stages (Birkhead 1982, Arvidsson 1992, Hanski 1994). Orange-crowned Warbler (Vermivora celata) pair members continue to associate closely with each other even when the female begins incubating her clutch (Gilbert 1994). Mountain Bluebirds (Sialia currucoides) also continue to associate closely throughout the nesting cycle (Power and Doner 1980); however because this species is multi-brooded, males may continue guarding their mate to ensure paternity of a second brood. Results of our study suggest intra-pair distance is not a simple measure of mate-guarding, at least in Red-faced Warblers. In 1992, a year with low nesting success, male Red-faced Warblers stayed closer to females during incubation, ostensibly a stage of nonfertility, than during egg laying or nest building. However, females did not initiate the ma- jority of pair movements. During 1993, a year with typical nesting success, intra-pair distances were similar for incubation and nest-building stages, and closer than during egg-laying. Moreover, females initiated the majority of pair movements even during incubation. Thus, Redfaced Warblers showed behavior unusual among reported studies in exhibiting high male attendance during incubation.

Males may maintain short intra-pair distances during incubation due to the ease with which they can stay in close contact with their mate. Activity patterns of nesting females may make it easier to predict their movements during both nest building and incubation, allowing males to concentrate their attendance behaviors. When females are building nests, their activity is spatially restricted; females return repeatedly to the same locations to collect nesting material and carry material back to the nest. When females are incubating eggs, their movements are temporally predictable; females tend to incubate for 20-30 min then leave the nest and forage for 610 min (Barber and Martin, pers. observ.). Females chip just prior to leaving the nest, providing an audible cue to their mate if he is out of visual contact (Barber and Martin, pers. observ.). This regular schedule and vocal cue allow males to concentrate their attendance activity during the time their mate is foraging. When the female is on the nest, the male can engage in other activities that might distract from staying in close contact with her including foraging, maintaining territory boundaries, and seeking extra-pair copulations. On the other hand, there is no real spatial or temporal predictability to female movements or location during egg-laying, which may make male attendance more difficult.

Of course, this explanation may account for opportunity, but does not account for motive: why do males continue to attend or guard females during incubation? Moreover, it does not explain why Red-faced Warblers exhibit close intra-pair distances and following behavior during incubation, when such behavior has not been observed in most other species that still exhibit the temporal and spatial predictability of incubation behavior (Birkhead 1982, Arvidsson 1992, Hanski 1994).

One possible explanation for continued close association of pair members may be that males aid the female while she is off the nest foraging 
during incubation. However, males cannot lead their mates to good foraging sites when the males are following females, and males rarely feed their mates (Martin and Ghalambor, unpubl. data). Alternatively, males may act as sentinels to scan for predators and thereby allow females to reduce their need for scanning and increase their foraging efficiency while off the nest.

Another possible explanation for continued close association during incubation might be future paternity related to risk of nest failure. Males may remain closer to their mates when likelihood of nest failure is high. The results are mixed. Intra-pair distance was smallest during incubation in 1992 when nesting success was unusually low, but each pair member initiated a similar proportion of movements during this stage. More importantly, female Red-faced Warblers do not appear to retain sperm storage tubules between nesting attempts and after egglaying (J. Briskie, pers. comm.). Thus, protection of future paternity seems an unlikely answer.

Rather than future paternity per se, males may respond to the proximate cue of paternity risk as reflected by intrusion rates. Extra-pair males intruded during the incubation stage more than the egg laying stage, which might explain the closer intra-pair distances during incubation (see above, also Fig. 1). Generally, males intruding into breeding territories seemed to be seeking extra-pair copulations (Møller 1987, Moore 1994). An intruding male would repeatedly sneak onto the territory when a female was building the nest. The intruder hid in the vegetation as close to the female as possible until an opportunity to solicit the female arose or until chased from the territory by the female's mate (P. Barber, pers. observ.). Thus, intrusion rate may provide an index of male driven extra-pair copulatory pressure. If females actively seek extra-pair copulations, intrusion rate may not be related to paternity loss.

Evidence that intrusions reflect extra-pair copulation pressure is suggested by the fact that more intrusions occurred during nest building than other stages, and nest-building is the stage of greatest copulatory activity (Birkhead and Møller 1993). Moreover, intrusion rate was negatively correlated with intra-pair distance during both nest building and across all stages, suggesting males view intrusions as a threat to their paternity. Additional evidence that males re- spond to intrusions was found during incubation in 1993. Females were most likely to initiate movements during nest building, egg laying, and incubation in 1993, when a large number of intrusions occurred. When the number of intrusions was lower, during incubation in 1992, males and females initiated similar proportions of movements. Thus, close intra-pair distances and males following female-initiated movements during incubation may be a response to increased intrusion rates during incubation, as a proximate index of risk of extra-pair paternity. The increase in intrusions during incubation, in turn, may simply reflect increased opportunity of males to explore neighboring territories while their female is on the nest.

The significance of males maintaining a higher position in the vegetation relative to their mate is unclear, but several explanations are possible. Such positioning may allow partitioning of food resources within the territory by sexes foraging at different heights. Yet, resource partitioning, as seen in Downy Woodpeckers (Picoides pubescens) (Peters and Grubb 1983), did not appear to drive height differences. The relative heights of Red-faced Warbler pair members seemed to shift continually during foraging and no intra-pair aggression was observed. Males may stay above females to obtain a better view of the area around females to guard against extra-pair copulations (Hobson and Sealy 1989). A male may benefit from being higher because he is more likely to see intruders. However, males did not appear to be tracking females. That is, males did not stay directly above females, but were simply higher in the vegetation. Alternatively, males may stay above females to obtain a better view of the area around females to warn her of any potential predators (Birkhead 1979) and, thereby, allow her to forage more efficiently.

Height differences between pair members also may be an artifact of the activities in which each sex was engaged. Male activities, such as singing, tend to take place high in the vegetation, whereas females tended to be near the ground, collecting nest material, and nest building. These activities could easily lead to height differences between pair members.

Male Red-faced Warblers do not appear to fit the typical mate guarding pattern. Males do appear to modify their behavior based upon intrusions by extra-pair males and their mate's repro- 
ductive status. In years with low nesting success, males continue to maintain shorter distances to their mates during incubation. In years with high intrusion rates, males forego movement initiations during incubation. Males may continue to follow their mate because they are protecting the female from predators (Birkhead 1979, Hobson and Sealy 1989) or protecting their paternity for any future nesting attempts within that year. Further research is needed to determine if continuing to mate guard into incubation is a general pattern for species inhabiting dense forests or something unique to Red-faced Warblers.

\section{ACKNOWLEDGMENTS}

We thank the many field assistants of the 1992 and 1993 Mogollon Rim crew for help locating and monitoring nests. We thank Arizona Game and Fish Department, Blue Ridge Ranger Station of the Coconino National Forest, and Chevlon Ranger Station of the Apache-Sitgreaves National Forest for their support of this work. This study was supported by grants from the National Science Foundation (BSR-8614598, BSR9006320, DEB-9407587, DEB-9527318), and the BBIRD (Breeding Biology Research and Monitoring Database) program under the Global Change Research Program of the National Biological Service. Thanks to J. Dunn and C. Paine for their help with statistical methods. PMB thanks Arkansas Audubon Trust and Sigma Xi; without their financial support this research would not have been possible. Special thanks to D. Barber and L. Garner who were gracious enough to review and provide insightful comments on earlier versions of this manuscript. We thank B. Arvidsson and anonymous reviewers for their constructive comments that improved the quality of this manuscript.

\section{LITERATURE CITED}

ARvidsson, B. L. 1992. Copulation and mate guarding in the Willow Warbler. Anim. Behav. 43:501509.

BiRKHEAD, T. R. 1979. Mate-guarding in the Magpie, Pica pica. Anim. Behav. 27:866-874.

BIRKHEAD, T. R. 1982. Timing and duration of mateguarding in magpies Pica pica. Anim. Behav. 30: $277-283$.

Birkhead, T. R., L. Atkin, AND A. P. Møller. 1987. Copulation behavior of birds. Behaviour 101:101138.

Birkhead, T. R., AND A. P. Møller. 1992. Sperm competition in birds. Academic Press, New York.

BirkHEAD, T. R., AND A. P. MøLler. 1993. Why do male birds stop copulating while their partners are still fertile? Anim. Behav. 45:105-118.

Dixon, A., D. Ross, S. L. C. O'MAlley, AND T. BuRKE. 1994. Paternal investment inversely related to degree of extra-pair paternity in the Reed Bunting. Nature 371:698-700.

GILBERT, W. M. 1994. Intrusions, and resident pair responses, during the breeding cycle of the Orange-crowned Warbler. J. Avian Biol. 5:105-111.

HANSKI, I. K. 1994. Timing of copulations and mate guarding in the Chaffinch Fringilla coelebs. Ornis Fennica 71:17-25.

HARRISON, H. H. 1984. Wood Warblers' world. Simon and Schuster, New York.

Hobson, K. A., And S. G. Sealy. 1989. Mate guarding in the Yellow Warbler Dendroica petechia. Ornis Scand. 20:241-249.

MARTIN, T. E. 1998. Are microhabitat preferences of coexisting species under selection and adaptive? Ecology, in press.

MARTin, T. E., AND P. M. BARber, 1995. Red-faced Warbler (Cardellina rubrifrons). In A. Poole and F. Gill [eds.], The birds of North America, No. 152. The Academy of Natural Sciences, Philadelphia, and The American Ornithologists' Union, Washington, DC

MøLler, A. P. 1987. Intruders and defenders on avian breeding territories: the effect of sperm competition. Oikos 48:47-54.

MølleR, A. P. 1988. Paternity and parental care in the swallow, Hirundo rustica. Anim. Behav. 33:9961005.

Monson, G. 1957. Red-faced warbler, p. 231-232. In L. Griscom and A. Sprunt Jr. [eds.], The warblers of America. Devin-Adair, New York.

Moore, P. M. 1994. Mate guarding and cuckoldry in Red-faced Warblers, Cardellina rubrifrons. M.Sc. thesis, Univ. Arkansas, Fayetteville, AR.

Peters, W. D., AND T. C. GRUBb JR. 1983. An experimental analysis of sex-specific foraging in the Downy Woodpecker, Picoides pubescens. Ecology 64:1437-1443.

Power, H. W., AND C. G. P. DONER. 1980. Experiments on cuckoldry in the Mountain Bluebird. Am. Nat. 116:689-704.

Pyle, P., S. N. G. Howell, R. P. Yunick, ANd D. F. DESANTE. 1987. Identification guide to North American passerines. Slate Creek Press, Bolinas, CA.

SAS Institute InC. 1985. SAS/STAT user's guide. Release 6.0. SAS Institute Inc., Cary, NC.

SundBerG, J. 1994. Paternity guarding in the Yellowhammer (Emberiza citrinella): a detention experiment. J. Avian Biol. 25:135-141.

WESTNEAT, D. F. 1988. Male parental care and extrapair copulations in the Indigo Bunting. Auk 105: $149-160$. 